\title{
Optimal Systemic Treatment for Early Triple-Negative Breast Cancer
}

\author{
Jenny Furlanetto Sibylle Loibl \\ GBG Forschungs GmbH, Neu Isenburg, Germany
}

\section{Keywords}

Triple-negative breast cancer - Early breast cancer . Guidelines · Treatment

\begin{abstract}
Background: Approximately $10-15 \%$ of all breast tumors are triple-negative breast cancer (TNBC). TNBC have a higher risk of relapse and distant metastases compared to other subtypes. The optimal systemic management of TNBC according to national and international guidelines is discussed herein. Summary: Anthracycline/taxane-based chemotherapy for patients with TNBC either in the neoadjuvant (NACT) or the adjuvant setting is considered standard of care. Exceptions are small tumors and a low-risk histology, in which chemotherapy can be spared. Dose-dense therapy is more effective in preventing recurrence and increasing survival. The use of nab-paclitaxel instead of a solvent-based taxane can lead to higher pathological complete response $(p C R)$ rates and better outcomes. Platinum agents are effective in increasing $\mathrm{PCR}$ when added to anthracycline/taxane-based chemotherapy at the cost of increased toxicity. Long-term outcome data are lacking. In patients without a $\mathrm{pCR}$, capecitabine leads to improved outcomes. Key Messages: The standard treatment approach of TNBC is anthracycline/ taxane-based chemotherapy, preferably within the NACT
\end{abstract}

setting. Dose-dense schedules as well as platinum should be considered in the NACT setting. For patients without a pCR, capecitabine is an option to improve the outcome. The role of nab-paclitaxel is under debate. In case of immunogenic tumors, checkpoint inhibitors are promising new agents that merit further investigation.

(c) 2020 S. Karger AG, Basel

\section{Introduction}

Triple-negative breast cancer (TNBC) accounts for approximately $10-15 \%$ of all newly diagnosed breast tumors and is characterized by a lack of expression of the estrogen (ER), progesterone (PgR), and human epidermal growth factor 2 receptors (HER2) [1]. The recently updated guidelines define a tumor sample as $\mathrm{ER} / \mathrm{PgR}$ negative if $<1 \%$ of the tumor cell nuclei are immunoreactive [2]. However, a new category, i.e., ER/PgR low, has been implemented, which is biologically very much like TNBC [3]. TNBC is typically diagnosed at a younger age [4]. At diagnosis, the majority of TNBC patients present with stage T2 or T3 and have involved lymph nodes and positive lymph vascular invasion [5]. The locoregional relapse rate appears to be similar to those of other molecular subgroups, but TNBC is associated with higher rates of dis- 
tant metastases [6], especially visceral ones, with a lower prevalence of bone metastases [7]. Most TNBC tend to have an aggressive course and a worse prognosis, with a high mortality rate [6].

Lately, there has been major progress in understanding TNBC, with the assertion that the use of standard markers is not enough to account for the complexity and heterogeneity of TNBC. Histopathological characterization is necessary to identify those subtypes with a better prognosis, such as adenoid cystic or metaplastic subtypes that might be treated with a less aggressive approach [8]. As highlighted by gene expression profile analyses, for the additional subclassification of TNBC, immune markers, androgen receptors, stem cells, basal markers, and the mesenchymal phenotype should be considered. In particular, based on the Vanderbilt classification, 4 molecular subtypes can be identified, with different histopathologies, gene expression profiles, prognoses, and treatment responses [9]. The treatment options for early TNBC are limited. Anthracycline/taxane-based chemotherapy is still the fulcrum of the therapy in the early setting. However, some steps forward have been made in recent years. Studies have shown that the addition of platinum can lead to higher pCR rates and might be considered in selected patients (Tables 1,2). Furthermore, in case of residual disease after NACT, capecitabine has demonstrated efficacy in improving patient outcomes [10]. In an attempt to exploit the molecular diversity of TNBC, several agents have been tested targeting specific structures or signaling pathways essential for cell proliferation, invasion, and angiogenesis. Checkpoint, PARP, and AKT inhibitors are among the most important agents under investigation, with encouraging preliminary efficacy results. Adherence to guidelines when treating patients with TNBC improves outcomes [11]. In this review the optimal treatment approach for early TNBC defined by the most recognized international [12-15] and German national [16] guidelines are presented (Table 1), and studies leading to these recommendations are discussed (Table 2).

\section{Predictive Biomarkers in Early TNBC}

$B R C A 1 / 2$ are tumor suppressor genes that encode proteins involved in the repair of DNA double-strand breaks through the homologous recombination repair pathway. Members of the PARP family of enzymes are central to the repair of DNA single-strand breaks. Fifteen to twenty percent of unselected TNBC have a $g B R C A$ mutation (m) [17]. TNBC patients without $g B R C A \mathrm{~m}$ have a somatic mutation in the homologous recombination signaling pathway (BRCAness). $g B R C A m$ and BRCAness statuses are associated with an increased sensitivity to chemother- apy and with better outcomes [17, 18]. Cells with $\mathrm{gBRCAm}$ are sensitive to PARP inhibition due to the synthetic lethality mechanism, resulting in an incapacity for DNA repair [19]. As gBRCAm is associated with a higher pathological complete response ( $\mathrm{pCR}$ ) rate and a prognostic impact in patients with TNBC [20], assessment of the gBRCA status should be considered in the early setting.

The results of studies with checkpoint inhibitors [21] have shown the importance of immune marker assessment in TNBC. TNBC are highly immunogenic as reflected by high levels of stromal tumor-infiltrating lymphocytes (TIL). TIL have a predictive and prognostic role, especially in TNBC [22]. In the early setting PD-L1 positivity on immune cells leads to higher pCR rates; in the advanced setting it leads to improved outcomes. Based on the results of IMpassion 130, the FDA approved the combination of nab-paclitaxel plus atezolizumab as first-line therapy for metastatic PD-L1+ TNBC. PD-L1 testing on immune cells is recommended in patients with advanced TNBC to consider this combination therapy.

As PD-L1 is a dynamic marker and differences exist in the types of assay used and in PD-L1 assessment, additional predictive biomarkers are under investigation. A high tumor mutational burden is associated with a higher neoantigen burden and increased T-cell infiltration. Recently, it was shown that hypermutated breast cancers, like tumors with a mismatch repair deficiency, seem to benefit from PD-1 inhibitor therapy independently of the underlying mutational process [23]. Further investigation is needed.

\section{Management of TNBC: Evidence So Far}

Despite it being a very heterogeneous disease, the treatment of patients with early TNBC is still founded on the administration of anthracycline/taxane-based chemotherapy. In a meta-analysis including women with hormone receptor (HR)-negative breast cancer treated in trials of non-taxane-based chemotherapy versus none, adjuvant chemotherapy reduced the 10 -year risk of recurrence and breast cancer mortality [24]. In a retrospective analysis of patients enrolled into 3 randomized trials of anthracycline/taxane-based chemotherapy, dosedense anthracycline/taxane-based chemotherapy lowered the rate of recurrence and death by more than $50 \%$ compared to low-dose anthracycline-based chemotherapy in HR-negative, node-positive breast cancer [25]. A meta-analysis using data of 100,000 women showed a reduced breast cancer mortality in patients receiving anthracycline/taxane-based chemotherapy. Proportional risk reductions were little affected by HR status [26]. 
Table 1. International and national guidelines and treatment recommendations

\begin{tabular}{|c|c|c|}
\hline Guidelines & Recommendations & LoE \\
\hline $\begin{array}{l}\text { Neoadjuvant setting } \\
\text { ASCO (2016) [14] }\end{array}$ & - Not applicable & \\
\hline NCCN (V 1.2020) [13] & $\begin{array}{l}\text { - Preferred option over adjuvant treatment if } \mathrm{T} \geq 2 \text { or } \mathrm{N} \geq 1 \\
\text { - Regimens recommended in the adjuvant setting may be considered in the NACT setting; weekly paclitaxel or } \\
\text { docetaxel + carboplatin are further recommended regimens for patients with TNBC } \\
\text { - Several studies have shown improved pCR rates with incorporation of platinum; their routine use is not } \\
\text { recommended for most patients (including } B R C A \text { mutation carriers) but might be considered in selected patients } \\
\text { (such as those for whom achieving better local control is necessary) }\end{array}$ & $2 \mathrm{~A}$ \\
\hline ESMO (2015) [12] & $\begin{array}{l}\text { - Addition of a platinum compound (carboplatin) to NACT allows for an increase in the } \mathrm{pCR} \text { rate, particularly } \\
\text { in those carrying deleterious } B R C A 1 / 2 \text { or } R A D \text { mutations or in patients with a family history of breast/ovarian } \\
\text { cancer; the effect of those compounds on long-term outcomes is unknown }\end{array}$ & IB \\
\hline AGO (V 1.2019) [16] & $\begin{array}{l}\text { - If chemotherapy is indicated NACT should be preferred over adjuvant therapy: } \\
\text { Conventionally dosed AT-based CT } \\
\text { Dose-dense CT (AT-based including a weekly schedule) } \\
\text { NACT platinum-containing CT (irrespectively of BRCA status) }\end{array}$ & $\begin{array}{l}\text { AGO GoR + } \\
\text { AGO GoR ++ } \\
\text { AGO GoR + }\end{array}$ \\
\hline $\begin{array}{l}\text { St. Gallen International } \\
\text { Consensus (2019) [15] }\end{array}$ & $\begin{array}{l}\text { - Preferred initial approach in women with stage II or III TNBC (AC/T CT }+/ \text { - platinum) } \\
\text { - Platinum-based CT: against the routine inclusion of platinum in women already slated to receive A-, T-, and } \\
\text { alkylator-based regimens; in favor of their inclusion among women with known, deleterious g BRCA1/2 } \\
\text { mutations (limited data, opinion not unanimous) } \\
\text { - Dose-dense treatment: preferred approach for AT-based neo/adjuvant CT regimens } \\
\text { - Neoadjuvant trials demonstrate that addition of an anti-PDL1 (durvalumab) or anti-PD1 (pembrolizumab) } \\
\text { agent to standard CT improves the rate of pCR in TNBC }\end{array}$ & $\begin{array}{l}\text { Expert } \\
\text { opinion }\end{array}$ \\
\hline $\begin{array}{l}\text { Adjuvant setting } \\
\text { ASCO (2016) [14] }\end{array}$ & $\begin{array}{l}\text { - TNBC patients with T }>5 \mathrm{~mm} \mathrm{N0} \text { are considered at high risk and are therefore candidates for CT } \\
\text { - Patients with early-stage, HER2-negative breast cancer with residual disease following standard AT-based } \\
\text { NACT may be offered up to } 6-8 \text { cycles of adjuvant capecitabine } \\
\text { - Platinum salts should not be routinely administered until efficacy data become available }\end{array}$ & $\begin{array}{l}\text { Evidence } \\
\text { quality: } \\
\text { intermediate }\end{array}$ \\
\hline NCCN (V 1.2020) [13] & $\begin{array}{l}\text { - The use of a platinum agent is not recommended; if included in an A-based regimen, the optimal sequence of } \\
\text { chemotherapy and choice of T agent is not established } \\
\text { - In patients with residual disease after NACT with A-, T- and alkylator-based CT: capecitabine; if indicated, it } \\
\text { should follow completion of radiotherapy }\end{array}$ & $2 \mathrm{~A}$ \\
\hline ESMO (2015) [12] & $\begin{array}{l}\text { - CT is recommended in the vast majority of TNBC (exception: secretory juvenile, apocrine, or adenoid cystic } \\
\text { carcinomas); CT is usually administered for } 12-24 \text { weeks } \\
\text { - The use of dose-dense schedules (with G-CSF) should be considered in highly proliferative tumors } \\
\text { - The use of platinum compounds is not recommended for routine use (independently of } g B R C A 1 / 2 \text { status) }\end{array}$ & $\begin{array}{l}\text { IA } \\
\text { IB } \\
\text { No LoR }\end{array}$ \\
\hline AGO (V 1.2019) [16] & $\begin{array}{l}\text { - Capecitabine containing regimen in the postneoadjuvant setting: } \\
\text { generally } \\
\text { in non-pCR (up to } 8 \text { courses) } \\
\text { - Platinum-containing regimen }\end{array}$ & $\begin{array}{l}\text { AGO GoR - } \\
\text { AGO GoR + } \\
\text { AGO GoR + }\end{array}$ \\
\hline $\begin{array}{l}\text { St. Gallen International } \\
\text { Consensus (2019) [15] }\end{array}$ & $\begin{array}{l}\text { - The adjuvant approach is typically used in stage I tumors: } \\
\text { Stage T1cN0 or higher: AC/T CT id the preferred regimen for many women } \\
\text { Stage T1ab }(\leq 1 \mathrm{~cm}) \text { N0: preference for a TC regimen without A (majority of panelists) } \\
\text { T1a }(\leq 0.5 \mathrm{~cm}) \text { N0: CT on a case-by-case basis } \\
\text { - Women with TNBC and residual tumor after NACT should consider capecitabine in the adjuvant setting } \\
\text { - Dose-dense treatment: preferred approach for AT-based neo/adjuvant chemotherapy regimens }\end{array}$ & \\
\hline
\end{tabular}

A, anthracycline; ASCO, American Society of Clinical Oncology; C, cyclophosphamide; CT, chemotherapy; ESMO, European Society for Medical Oncology; g, germline; G-CSF, granulocyte colony-stimulating factor support; GoR, grade of recommendation: LoE, level of evidence; T, taxane; V, version.

Based on this evidence, guidelines recommend the use of chemotherapy for patients with TNBC either in the neoadjuvant (NACT) or in the adjuvant setting, with the possible exception of small tumors and a low risk histology. Due to discordant results, the use of nab-paclitaxel is still under debate [27-30]. Arbeitsgemeinschaft Gynäko- logische Onkologie (AGO) guidelines recommend the use of nab-paclitaxel instead of paclitaxel in the NACT setting [16]. Conversely, National Comprehensive Cancer Network (NCCN) guidelines state that nab-paclitaxel may substitute soluble taxanes due to medical necessity (e.g., hypersensitivity) [13]. 


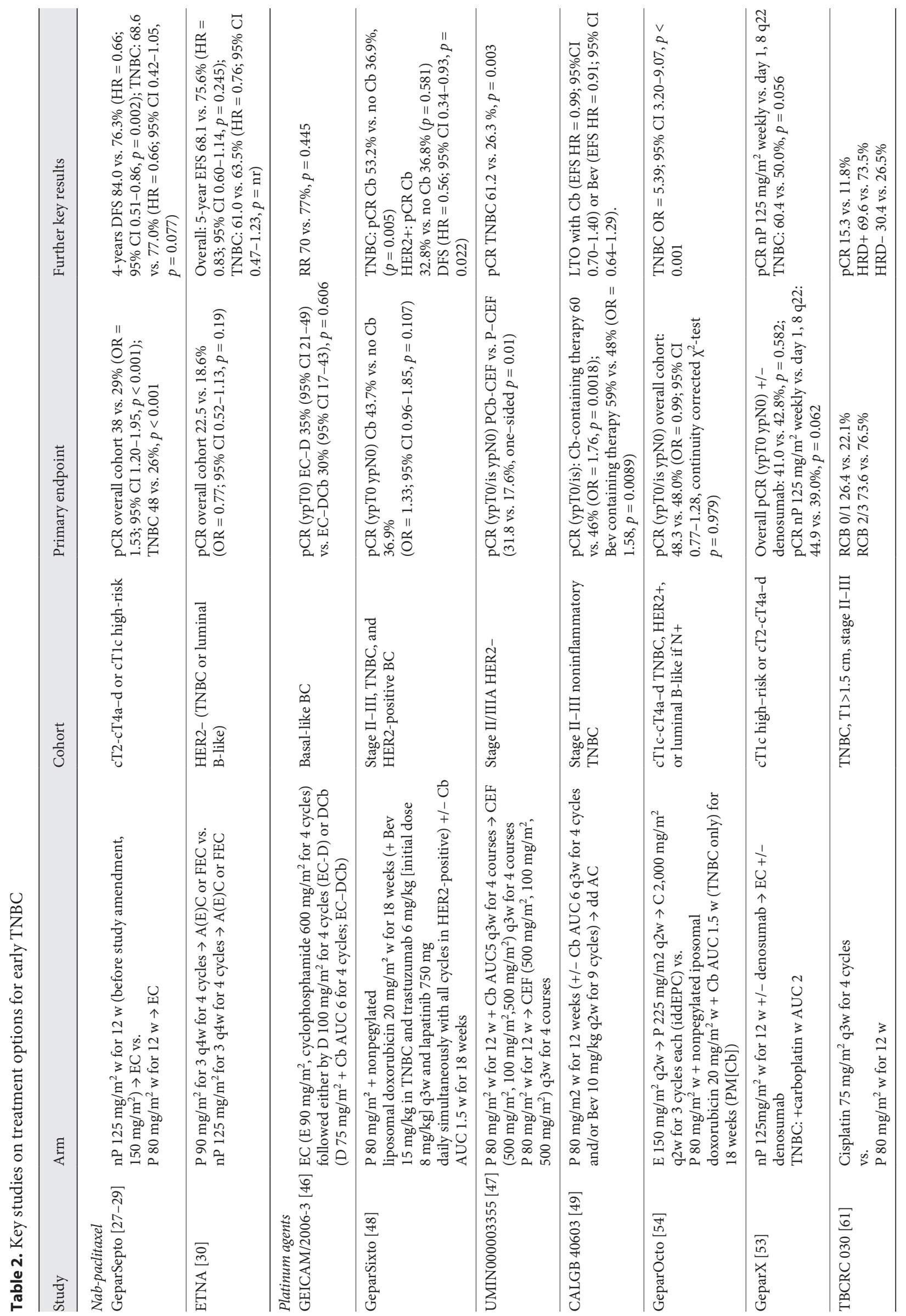




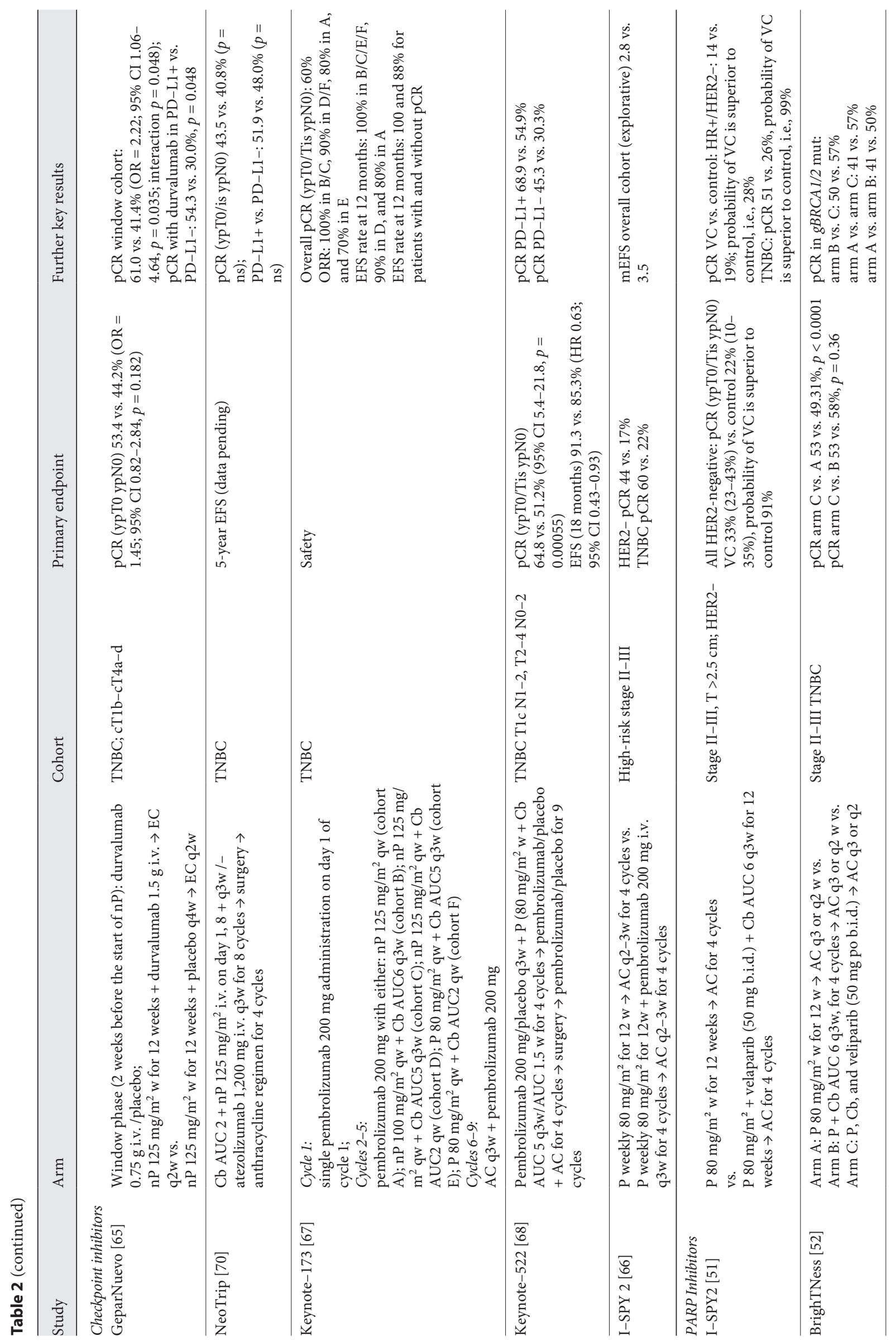




\section{Treatment Setting}

Administration of chemotherapy in the neoadjuvant setting is the preferred option as it permits prompt delivery of effective systemic therapy to downstage the tumor (aiming at more conservative surgery), to monitor the treatment response, and to identify chemotherapy-resistant tumors [31] that could benefit from non-cross-resistant therapy after surgery [10]. Moreover, TNBC obtained the highest pCR rate among all of the subtypes [32]. Even if TNBC is associated with a decreased 3-year disease-free survival (DFS) and overall survival (OS) [33], pCR is associated with improved outcomes [34]. In the rare event of progression under NACT [27], surgery should be promptly performed. The chemotherapy regimens used are the same in the neoadjuvant and adjuvant settings.

\section{Postneoadjuvant Therapy}

Patients without $\mathrm{pCR}$ have a substantial risk of relapse within the first 2-3 years. Several trials have been initiated to improve the outcomes by applying a non-crossresistant drug after surgery.

The CREATE-X trial [10] is the first study investigating the use of capecitabine versus observation as a postneoadjuvant approach for patients without a pCR after anthracycline/taxane-based NACT. The trial was terminated early as the prespecified interim analysis met the primary endpoint, i.e., DFS, in favor of capecitabine (HR $=0.70 ; 95 \%$ CI $0.53-0.92 ; p=0.01)$. Patients with TNBC derived the greatest benefit $(\mathrm{HR}=0.58$; $95 \%$ CI 0.39 0.87 ) even if a statistically significant interaction with $\mathrm{HR}$ status could not be shown. The CIBOMA/2004-01 [35] randomized node-positive or node-negative TNBC patients with tumors $\geq 1 \mathrm{~cm}$ treated with anthracycline/taxane-based chemotherapy in the (neo)adjuvant setting to capecitabine or observation after surgery, independently of pCR. The study failed to show a statistically significant increase in DFS by adding capecitabine. Recently, an individual patient data meta-analysis of capecitabine showed improved DFS and OS for TNBC patients when capecitabine was given in addition to other systemic treatments [36]. Similar results were found in 2 further trial level meta-analyses [37, 38].

Guidelines recommend the use of capecitabine in TNBC patients with residual disease after NACT. Of note, none of the patients received carboplatin as part of the (neo)adjuvant therapy. In patients aged $\geq 65$ years, doses of $1,000 \mathrm{mg} / \mathrm{m}^{2}$ orally twice daily should be considered to avoid toxicities leading to dose reductions [39].

Postneoadjuvant studies investigating the role of platinum agents alone (NCT02445391) or in combination 
with a PARP inhibitor (rucaparib NCT01074970), olaparib (NCT02032823) avelumab (NCT02926196), and pembrolizumab (NCT02954874) are ongoing.

\section{Dose-Dense and Dose-Intense Chemotherapy}

According to the Goldie-Coldman [40] and NortonSimon [41] hypotheses, outcomes can be improved by reducing the intervals between cycles and using chemotherapy sequentially at higher doses rather than concomitantly but at a lower dose. However, individual trial results have been discordant [42]. Recently, the EBCTCG conducted a meta-analysis of early breast cancer trials comparing 2-weekly dose-dense versus standard 3-weekly schedules and sequential versus concurrent administration of anthracycline/taxane-based chemotherapy [43]. With a median follow-up of 7.4 years a significant $3.4 \%$ absolute reduction in recurrence with dose intensification versus standard schedule chemotherapy was shown. The proportional reduction in recurrence was similar for ER-negative and ER-positive tumors. Additionally, the absolute 10 -year breast cancer mortality rate was improved by $2.4 \%$. Despite some limitations [44], these results suggest that especially in patients with high-risk breast cancer the dose-dense approach should be considered supported by granulocyte colony-stimulating factor.

European guidelines recommend the use of a dosedense regimen in patients with high-risk breast cancer. NCCN guidelines list dose-dense anthracycline/taxanebased chemotherapy among the preferred options for HER2-negative tumors.

\section{Role of Platinum Agents}

TNBC is often associated with a deficiency in $B R C A$ driven DNA repair mechanisms, leading to a higher sensibility to interstrand cross-linking agents damaging the DNA, such as platinum agents [45-47].

In the GeparSixto study, an increased pCR rate was seen in patients with TNBC when carboplatin (AUC 2) was added to anthracycline/taxane-based chemotherapy. Carboplatin was associated with a higher toxicity, but the frequency of grade 3-4 adverse events (AE) decreased when the dose was reduced to AUC 1.5 [48]. The pCR benefit translated into a significantly better DFS [17]. Similarly, in the CALGB 40603 study, the addition of either carboplatin or bevacizumab increased the $\mathrm{pCR}$ rate. However, patients assigned to either carboplatin or bevacizumab were less likely to complete the treatment without dose modifications due to AE [49]. Conversely to GeparSixto, the CALGB 40603 study did not show any improvement in outcomes by adding carboplatin or bevacizumab [50]. Based on the I-SPY2 results [51], the BrighTNess trial investigated the use of carboplatin and velaparib in patients with stage II-III TNBC. Carboplatin increased the $\mathrm{pCR}$ rate compared to paclitaxel alone and independently by the use of velaparib. Grade 3-4 AE were more common in patients receiving carboplatin, whereas veliparib did not substantially increase toxicity [52]. Of note, $42 \%$ of patients required a reduction in the dose of carboplatin from AUC 6 to AUC 5. The recommended dose is therefore carboplatin AUC 1.5 weekly or AUC 5 $\mathrm{q} 3 \mathrm{w}$ when given in addition to paclitaxel. The efficacy of carboplatin in TNBC was further confirmed in the GeparX study [53]. The GeparOcto study showed that an intense dose-dense regimen including high-dose cyclophosphamide was equally effective to the anthracycline/ taxane-based regimen including conventionally dosed carboplatin and appeared to be more feasible [54].

Contrary to data obtained in the metastatic setting, the carboplatin effect was independent of $g B R C A$ status. Patients with $g B R C A m$ had in general a higher $\mathrm{pCR}$ rate compared to wild type ones, but the increase in pCR with the addition of carboplatin was more prominent in the wild type cohort $[17,18,55-58]$. One explanation of the different results could be the single versus combination therapy or the treatment setting.

Results of meta-analyses are consistent [59, 60]. Even though only a few small studies assessed the role of cisplatin [61], it seems to be as effective as carboplatin in increasing the $\mathrm{pCR}$ rate, but with a different safety profile $[62,63]$. A head-to-head study of 4 cycles of weekly carboplatin (AUC 2) or cisplatin $\left(25 \mathrm{mg} / \mathrm{m}^{2}\right)$ and paclitaxel $\left(80 \mathrm{mg} / \mathrm{m}^{2}\right)$ showed similar pCR rates and outcomes for the 2 compounds. No significant differences were seen in terms of AE [64].

Many new trials have incorporated carboplatin as part of the standard regimen. Its use is recommended irrespectively of the BRCA status.

\section{Checkpoint Inhibitors}

Immunotherapy seems to be a very promising approach. In the GeparNuevo trial, the addition of durvalumab to anthracycline/taxane-based chemotherapy showed an increased pCR rate only in patients receiving durvalumab alone within the window phase. A priming effect of durvalumab has been hypothesized. In both arms, a significantly increased pCR was observed with higher stromal TIL, with a trend in PD-L1-positive tumors [65]. Encouraging results were also seen with pembrolizumab, which increased pCR rates in patients with early TNBC $[66,67]$. The Keynote-522 trial showed a higher pCR rate especially for patients with stage III or node-positive disease, regardless of $\mathrm{PD}-\mathrm{L} 1$ expression 
[68] and an improved outcome [69]. Atezolizumab did not increase the pCR rate when added to carboplatin and nab-paclitaxel, with long term results pending [70]. None of these checkpoint inhibitors have been approved for use in the early breast cancer setting so far.

\section{PARP Inhibitors}

Two randomized phase III trials, i.e., OlympiAD [71] and EMBRACA [72], have shown efficacy of PARP inhibitors compared to treatment of the physician's choice in the metastatic setting, leading to investigations in the early setting. In the the BrighTNess study, the use of veliparib seemed not to add benefit in terms of $\mathrm{pCR}$ when carboplatin was administered together with paclitaxel, with only minimally increased toxicities [51, 52]. Evidence from the metastatic setting where the addition of veliparib at $120 \mathrm{mg}$ per os b.i.d. to paclitaxel and carboplatin was investigated in the BROCADE 3 study, showing increased progression-free survival compared to chemotherapy alone without altering the toxicity profile, might suggest exploration of higher veliparib doses in the early setting. Talazoparib has also shown activity when administered as neoadjuvant monotherapy [73]. The phase III study is ongoing (NCT03499353). Finally, in the neoadjuvant GeparOLA study, olaparib added to paclitaxel in HER2-negative early breast cancer with homologous recombination deficiency was well tolerated. pCR results are promising but need further confirmation [74]. Results of several ongoing trials (OlympiA NCT02032823, PARTNERNCT03150576, and Rucaparib NCT03542175) are pending.

\section{AKT Inhibitors}

In the metastatic setting both ipatasertib and capivasertib have shown promising activity especially in patients with PIK3CA/AKT1/PTEN altered tumors [75,
76]. In the adaptive phase II I-SPY 2 trial, the AKT inhibitor MK-2206 plus standard NACT attained an estimated pCR rate of $40 \%$. compared to $22 \%$ with chemotherapy alone [77]. In the neoadjuvant FAIRLANE trial, the addition of ipatasertib to paclitaxel did not significantly increase the $\mathrm{pCR}$ rate. The overall response rate by MRI was numerically higher with ipatasertib. Notably, all patients with a complete response had PIK3CA/ AKT1/PTEN altered tumors [78]. Further studies are warranted.

\section{Conclusion}

Anthracycline/taxane-based chemotherapy remains the preferred standard option for patients with early TNBC, but many promising agents are on the horizon. The use of carboplatin is recommended irrespectively of $B R C A$ status. The role of PARP and AKT inhibitors in the early setting is still under investigation. The inclusion of checkpoint inhibitors in neoadjuvant therapy for high-risk patients is imminent. In patients with residual disease after NACT, adjuvant capecitabine is an option. BRCA status and immune marker assessment should be considered given their predictive and prognostic role.

\section{Acknowledgement}

Thanks go to Dr. Bianca Lederer for editorial support.

\section{Disclosure Statement}

The authors declare no conflict of interests.

\section{Author Contributions}

J.F. and S.L. contributed equally to this paper.

\section{References}

1 Dawson SJ, Provenzano E, Caldas C. Triple negative breast cancers: clinical and prognostic implications. Eur J Cancer. 2009 Sep;45:27-40.

2 Allison $\mathrm{KH}$, Hammond $\mathrm{EH}$, Dowsett M, et al. ASCO, CAP ER/PgR testing in breast cancer guideline update. J Clin Oncol. Forthcoming 2020.

3 Villegas SL, Lederer B, Untch M et al. Similarities between low hormone receptor positive and hormone receptor negative breast cancer: an analysis of 4366 patients from multicenter clinical trials. Cancer Res 2019;79:abstract P2-08-10

4 Dent R, Trudeau M, Pritchard KI, Hanna WM, Kahn HK, Sawka CA, et al. Triple-neg- ative breast cancer: clinical features and patterns of recurrence. Clin Cancer Res. 2007 Aug;13(15 Pt 1):4429-34.

5 Lebert JM, Lester R, Powell E, Seal M, McCarthy J. Advances in the systemic treatment of triple-negative breast cancer. Curr Oncol. 2018 Jun;25:S142-50.

6 Haffty BG, Yang Q, Reiss M, Kearney T, Higgins SA, Weidhaas J, et al. Locoregional relapse and distant metastasis in conservatively managed triple negative early-stage breast cancer. J Clin Oncol. 2006 Dec;24(36):5652-7.

7 Lin NU, Vanderplas A, Hughes ME, Theriault RL, Edge SB, Wong YN, et al. Clinicopatholog- ic features, patterns of recurrence, and survival among women with triple-negative breast cancer in the National Comprehensive Cancer Network. Cancer. 2012 Nov;118(22):5463-72.

8 Denkert C, Liedtke C, Tutt A, von Minckwitz G. Molecular alterations in triple-negative breast cancer-the road to new treatment strategies. Lancet. 2017 Jun;389(10087):2430-42.

9 Lehmann BD, Jovanović B, Chen X, Estrada MV, Johnson KN, Shyr Y, et al. Refinement of Triple-Negative Breast Cancer Molecular Subtypes: Implications for Neoadjuvant Chemotherapy Selection. PLoS One. 2016 Jun; 11(6):e0157368. 
10 Masuda N, Lee SJ, Ohtani S, Im YH, Lee ES, Yokota I, et al. Adjuvant capecitabine for breast cancer after preoperative chemotherapy. N Engl J Med. 2017 Jun;376(22):2147-59.

11 Schwentner L, Wöckel A, König J, Janni W, Ebner $\mathrm{F}$, Blettner $\mathrm{M}$, et al.; Brenda study group. Adherence to treatment guidelines and survival in triple-negative breast cancer: a retrospective multi-center cohort study with 9,156 patients. BMC Cancer. 2013 Oct;13(1):487.

12 Senkus E, Kyriakides S, Ohno S, Penault-Llorca F, Poortmans P, Rutgers E, et al.; ESMO Guidelines Committee. Primary breast cancer: ESMO clinical practice guidelines for diagnosis, treatment and follow-up. Ann Oncol. 2015 Sep;26:v8-30.

13 National Comprehensive Cancer Network. Breast cancer (version 1.2020). 2020. Available from: https://www.nccn.org/professionals/physician_gls/pdf/breast.pdf.

14 Denduluri N, Somerfield MR, Giordano SH Selection of Optimal Adjuvant Chemotherapy and Targeted Therapy for Early Breast Cancer: ASCO Clinical Practice Guideline Focused Update Summary. J Oncol Pract. 2018 Aug;14(8):508-10.

15 Burstein HJ, Curigliano G, Loibl S, Dubsky P Gnant M, Poortmans P, et al.; Members of the St. Gallen International Consensus Panel on the Primary Therapy of Early Breast Cancer 2019. Estimating the benefits of therapy for early-stage breast cancer: the St. Gallen International Consensus Guidelines for the primary therapy of early breast cancer 2019. Ann Oncol. 2019 Oct;30(10):1541-57.

16 AGO Breast Committee. Diagnosis and treatment of patients with primary and metastatic breast cancer: recommendations 2019. Available from: www.ago-online.de.

17 Loibl S, Weber KE, Timms KM, Elkin EP, Hahnen E, Fasching PA, et al. Survival analysis of carboplatin added to an anthracycline/ taxane-based neoadjuvant chemotherapy and HRD score as predictor of response-final results from GeparSixto. Ann Oncol. 2018 Dec; 29(12):2341-7

18 Pohl-Rescigno E, Hauke J, Loibl S, et al. Germline mutation status and therapy response in high-risk early-stage 2 breast cancer: a secondary analysis of the GeparOcto randomized clinical trial. JAMA Oncol. Forthcoming 2020.

19 Walsh CS. Two decades beyond BRCA1/2 homologous recombination, hereditary cancer risk and a target for ovarian cancer therapy. Gynecol Oncol. 2015 May;137(2):343-50.

20 Copson ER, Maishman TC, Tapper WJ, Cutress RI, Greville-Heygate S, Altman DG, et al. Germline BRCA mutation and outcome in young-onset breast cancer (POSH): a prospective cohort study. Lancet Oncol. 2018 Feb;19(2):169-80.

21 Schmid P, Adams S, Rugo HS, Schneeweiss A, Barrios CH, Iwata H, et al.; IMpassion130 Trial Investigators. Atezolizumab and nab-paclitaxel in advanced triple-negative breast cancer. N Engl J Med. 2018 Nov;379(22):2108-21.

22 Denkert C, von Minckwitz G, Brase JC, Sinn BV, Gade S, Kronenwett R, et al. Tumor-infiltrating lymphocytes and response to neoadjuvant chemotherapy with or without carboplatin in human epidermal growth factor receptor 2-positive and triple-negative primary breast cancers. J Clin Oncol. 2015 Mar;33(9):983-91.

23 Barroso-Sousa R, Jain E, Cohen O, Kim D, Buendia-Buendia J, Winer E, et al. Prevalence and mutational determinants of high tumor mutation burden in breast cancer. Ann Oncol. 2020 Mar;31(3):387-94.

24 Clarke M, Coates AS, Darby SC, Davies C, Gelber RD, Godwin J, et al.; Early Breast Cancer Trialists' Collaborative Group (EBCTCG). Adjuvant chemotherapy in oestrogen-receptor-poor breast cancer: patient-level metaanalysis of randomised trials. Lancet. 2008 Jan;371(9606):29-40.

25 Berry DA, Cirrincione C, Henderson IC, Citron ML, Budman DR, Goldstein LJ, et al. Estrogen-receptor status and outcomes of modern chemotherapy for patients with nodepositive breast cancer. JAMA. 2006 Apr; 295(14):1658-67.

26 Peto R, Davies C, Godwin J, Gray R, Pan HC, Clarke M, et al.; Early Breast Cancer Trialists' Collaborative Group (EBCTCG). Comparisons between different polychemotherapy regimens for early breast cancer: meta-analyses of long-term outcome among 100,000 women in 123 randomised trials. Lancet. 2012 Feb;379(9814):432-44.

27 Untch M, Jackisch C, Schneeweiss A, Conrad B, Aktas B, Denkert C, et al.; German Breast Group (GBG); Arbeitsgemeinschaft Gynäkologische Onkologie-Breast (AGO-B) Investigators. Nab-paclitaxel versus solvent-based paclitaxel in neoadjuvant chemotherapy for early breast cancer (GeparSepto-GBG 69): a randomised, phase 3 trial. Lancet Oncol. 2016 Mar;17(3):345-56.

28 Untch M, Jackisch C, Schneeweiss A, Schmatloch S, Aktas B, Denkert C, et al. NAB-Paclitaxel Improves Disease-Free Survival in Early Breast Cancer: GBG 69-GeparSepto. J Clin Oncol. 2019 Sep;37(25):2226-34.

29 Furlanetto J, Jackisch C, Untch M, Schneeweiss A, Schmatloch S, Aktas B, et al. Efficacy and safety of nab-paclitaxel $125 \mathrm{mg} / \mathrm{m} 2$ and nab-paclitaxel $150 \mathrm{mg} / \mathrm{m} 2$ compared to paclitaxel in early high-risk breast cancer. Results from the neoadjuvant randomized GeparSepto study (GBG 69). Breast Cancer Res Treat. 2017 Jun;163(3):495-506.

30 Gianni L, Mansutti M, Anton A, Calvo Martínez L, Bisagni G, Bermejo B, et al. Event-free survival analysis of the prospectively randomized phase III ETNA study with neoadjuvant nab-paclitaxel (nab-P) versus paclitaxel (P) followed by anthracycline regimens in women with HER2-negative high-risk breast cancer. J Clin Oncol. 2019;37:515.

31 Kaufmann M, Hortobagyi GN, Goldhirsch A, Scholl S, Makris A, Valagussa P, et al. Recommendations from an international expert panel on the use of neoadjuvant (primary) systemic treatment of operable breast cancer: an update. J Clin Oncol. 2006 Apr;24(12): 1940-9.

32 von Minckwitz G, Untch M, Blohmer JU, Costa SD, Eidtmann H, Fasching PA, et al. Definition and impact of pathologic complete response on prognosis after neoadjuvant chemotherapy in various intrinsic breast cancer subtypes. J Clin Oncol. 2012 May;30(15): 1796-804.
33 Liedtke C, Mazouni C, Hess KR, André F, Tordai A, Mejia JA, et al. Response to neoadjuvant therapy and long-term survival in patients with triple-negative breast cancer. Clin Oncol. 2008 Mar;26(8):1275-81.

34 Cortazar P, Zhang L, Untch M, Mehta K, Costantino JP, Wolmark N, et al. Pathological complete response and long-term clinical benefit in breast cancer: the CTNeoBC pooled analysis. Lancet. 2014 Jul;384(9938):164-72.

35 Lluch A, Barrios CH, Torrecillas L, Ruiz-Borrego M, Bines J, Segalla J, et al.; GEICAM Spanish Breast Cancer Group; CIBOMA (Iberoamerican Coalition for Research in Breast Oncology); and LACOG (Latin American Cooperative Oncology Group). Phase III Trial of Adjuvant Capecitabine After Standard Neo-/Adjuvant Chemotherapy in $\mathrm{Pa}$ tients With Early Triple-Negative Breast Cancer (GEICAM/2003-11 CIBOMA/2004-01). J Clin Oncol. 2020 Jan;38(3):203-13.

36 van Mackelenbergh M, Seither F, Möbus V et al. Effects of capecitabine as part of neo-/adjuvant chemotherapy: a meta-analysis of individual patient data from 12 randomized trials including 15,457 patients. Cancer Res. 2020; 80:abstract GS1-07.

37 Natori A, Ethier JL, Amir E, Cescon DW. Capecitabine in early breast cancer: a metaanalysis of randomised controlled trials. Eur J Cancer. 2017 May;77:40-7.

38 Jiang Y, Yin W, Zhou L, Yan T, Zhou Q, Du $\mathrm{Y}$, et al. First efficacy results of capecitabine with anthracycline- and taxane-based adjuvant therapy in high-risk early breast cancer: a meta-analysis. PLoS One. 2012;7(3):e32474.

39 Bajetta E, Procopio G, Celio L, Gattinoni L, Della Torre S, Mariani L, et al. Safety and efficacy of two different doses of capecitabine in the treatment of advanced breast cancer in older women. J Clin Oncol. 2005 Apr;23(10): 2155-61.

40 Coldman AJ, Goldie JH. Impact of dose-intense chemotherapy on the development of permanent drug resistance. Semin Oncol. 1987 Dec;14(4 Suppl 4):29-33.

41 Simon R, Norton L. The Norton-Simon hypothesis: designing more effective and less toxic chemotherapeutic regimens. Nat Clin Pract Oncol. 2006 Aug;3(8):406-7.

42 Kaufmann M, Eiermann W, Schuette M, et al. Long-term results from the neoadjuvant $\mathrm{Ge}$ parDuo trial: a randomized, multicenter, open phase III study comparing a dose-intensified 8 -week schedule of doxorubicin hydrochloride and docetaxel with a sequential 24-week schedule of doxorubicin hydrochloride/ cyclophosphamide followed by docetaxel regimen as preoperative therapy in patients with operable breast cancer. J Clin Oncol. 2010;28:537.

43 Gray R, Bradley R, Braybrooke J, Liu Z, Peto R, Davies L, et al.; Early Breast Cancer Trialists' Collaborative Group (EBCTCG). Increasing the dose intensity of chemotherapy by more frequent administration or sequential scheduling: a patient-level meta-analysis of 37298 women with early breast cancer in 26 randomised trials. Lancet. 2019 Apr; 393(10179):1440-52.

44 Hurvitz SA. Dose intensification of chemotherapy for early breast cancer in the age of de-escalation. Lancet. 2019 Apr;393(10179):1390-2. 
45 Joensuu H, Gligorov J. Adjuvant treatments for triple-negative breast cancers. Ann Oncol. 2012 Aug;23:vi40-5.

46 Alba E, Chacon JI, Lluch A, Anton A, Estevez L, Cirauqui B, et al. A randomized phase II trial of platinum salts in basal-like breast cancer patients in the neoadjuvant setting. Results from the GEICAM/2006-03, multicenter study. Breast Cancer Res Treat. 2012 Nov;136(2):487-93.

47 Ando M, Yamauchi H, Aogi K, Shimizu S, Iwata $\mathrm{H}$, Masuda $\mathrm{N}$, et al. Randomized phase II study of weekly paclitaxel with and without carboplatin followed by cyclophosphamide/ epirubicin/5-fluorouracil as neoadjuvant chemotherapy for stage II/IIIA breast cancer without HER2 overexpression. Breast Cancer Res Treat. 2014 Jun;145(2):401-9.

48 von Minckwitz G, Schneeweiss A, Loibl S, Salat C, Denkert C, Rezai M, et al. Neoadjuvant carboplatin in patients with triple-negative and HER2-positive early breast cancer (GeparSixto; GBG 66): a randomised phase 2 trial. Lancet Oncol. 2014 Jun;15(7):747-56.

49 Sikov WM, Berry DA, Perou CM, Singh B, Cirrincione CT, Tolaney SM, et al. Impact of the addition of carboplatin and/or bevacizumab to neoadjuvant once-per-week paclitaxel followed by dose-dense doxorubicin and cyclophosphamide on pathologic complete response rates in stage II to III triple-negative breast cancer: CALGB 40603 (Alliance). J Clin Oncol. 2015 Jan;33(1):13-21.

50 Sikov WM, Polley MY, Twohy E, Perou CM, Singh B, Berry DA, et al. CALGB (Alliance) 40603: long-term outcomes (LTOs) after neoadjuvant chemotherapy (NACT) +/- carboplatin $(\mathrm{Cb})$ and bevacizumab (Bev) in triplenegative breast cancer (TNBC). J Clin Oncol. 2019;37:591.

51 Rugo HS, Olopade OI, DeMichele A, Yau C, van 't Veer LJ, Buxton MB, et al.; I-SPY 2 Investigators. Adaptive randomization of veliparib-carboplatin treatment in breast cancer. N Engl J Med. 2016 Jul;375(1):23-34.

52 Loibl S, O’Shaughnessy J, Untch M, Sikov WM, Rugo HS, McKee MD, et al. Addition of the PARP inhibitor veliparib plus carboplatin or carboplatin alone to standard neoadjuvant chemotherapy in triple-negative breast cancer (BrighTNess): a randomised, phase 3 trial. Lancet Oncol. 2018 Apr;19(4):497-509.

53 Blohmer JU, Link T, Kümmel S, et al. Investigating denosumab as an add-on treatment to neoadjuvant chemotherapy and two different nab-paclitaxel schedules in a $2 \times 2$ design in primary breast cancer: first results of the GeparX study. Cancer Res 2020;80:abstract GS3-01.

54 Schneeweiss A, Möbus V, Tesch H, Hanusch C, Denkert C, Lübbe K, et al. Intense dosedense epirubicin, paclitaxel, cyclophosphamide versus weekly paclitaxel, liposomal doxorubicin (plus carboplatin in triple-negative breast cancer) for neoadjuvant treatment of high-risk early breast cancer (GeparOctoGBG 84): A randomised phase III trial. Eur J Cancer. 2019 Jan;106:181-92.

55 Telli ML, Metzger O, Timms K, Evans B, Vogel $\mathrm{D}$, Wei $\mathrm{H}$, et al. Evaluation of homologous recombination deficiency (HRD) status with pathological response to carboplatin +/- veliparib in BrighTNess, a randomized phase 3 study in early stage TNBC. J Clin Oncol. 2018;36:519.
56 Tutt A, Tovey H, Cheang MC, Kernaghan S, Kilburn L, Gazinska P, et al. Carboplatin in BRCA1/2-mutated and triple-negative breast cancer BRCAness subgroups: the TNT Trial. Nat Med. 2018 May;24(5):628-37.

57 Hahnen E, Lederer B, Hauke J, Loibl S, Kröber S, Schneeweiss A, et al. Germline Mutation Status, Pathological Complete Response, and Disease-Free Survival in Triple-Negative Breast Cancer: Secondary Analysis of the GeparSixto Randomized Clinical Trial. JAMA Oncol. 2017 Oct;3(10):1378-85.

58 Fasching PA, Loibl S, Hu C, Hart SN, Shimelis $\mathrm{H}$, Moore R, et al. BRCA1/2 Mutations and Bevacizumab in the Neoadjuvant Treatment of Breast Cancer: Response and Prognosis Results in Patients With Triple-Negative Breast Cancer From the GeparQuinto Study. J Clin Oncol. 2018 Aug;36(22):2281-7.

59 Poggio F, Bruzzone M, Ceppi M, Pondé NF, La Valle G, Del Mastro L, et al. Platinumbased neoadjuvant chemotherapy in triplenegative breast cancer: a systematic review and meta-analysis. Ann Oncol. 2018 Jul; 29(7):1497-508.

60 Wang D, Feng J, Xu B. A meta-analysis of platinum-based neoadjuvant chemotherapy versus standard neoadjuvant chemotherapy for triple-negative breast cancer. Future Oncol. 2019 Aug;15(23):2779-90.

61 Mayer EL, Abramson VG, Jankowitz RC, et al. TBCRC 030: a randomized phase II study of preoperative cisplatin versus paclitaxel in TNBC: evaluating the homologous recombination deficiency (HRD) biomarker. J Clin Oncol. 2019;37:507.

62 Byrski T, Huzarski T, Dent R, Marczyk E, Jasiowka M, Gronwald J, et al. Pathologic complete response to neoadjuvant cisplatin in BRCA1-positive breast cancer patients. Breast Cancer Res Treat. 2014 Sep;147(2):401-5.

63 Aguilar Martinez MC, Arce-Salinas C, Alvarado-Miranda $\mathrm{A}$, et al. Randomized phase II trial to evaluate the safety and efficacy of neoadjuvant cisplatin in combination with taxanes-anthracyclines vs taxanes-anthracyclines alone in locally advanced triple negative breast cancer. J Clin Oncol. 2015;33:e12024.

64 Huang L, Liu Q, Chen S, Shao Z. Cisplatin versus carboplatin in combination with paclitaxel as neoadjuvant regimen for triple negative breast cancer. OncoTargets Ther. 2017 Dec;10:5739-44.

65 Loibl S, Untch M, Burchardi N, Huober J, Sinn BV, Blohmer JU, et al. A randomised phase II study investigating durvalumab in addition to an anthracycline taxane-based neoadjuvant therapy in early triple-negative breast cancer: clinical results and biomarker analysis of GeparNuevo study. Ann Oncol. 2019 Aug;30(8):1279-88.

66 Nanda R, Liu MC, Yau C, et al. Effect of pembrolizumab plus neoadjuvant chemotherapy on pathologic complete response in women with early-stage breast cancer: an analysis of the ongoing phase 2 adaptively randomized ISPY2 trial. JAMA Oncol. Forthcoming 2020.

67 Schmid P, Salgado R, Park YH, MuñozCouselo E, Kim SB, Sohn J, et al. Pembrolizumab plus chemotherapy as neoadjuvant treatment of high-risk, early-stage triple-negative breast cancer: results from the phase $1 \mathrm{~b}$ open-label, multicohort KEYNOTE-173 study. Ann Oncol. 2020 May;31(5):569-81.

68 Schmid P, Park YH, Ferreira M, et al. Keynote-522 study of pembrolizumab + chemotherapy vs placebo + chemotherapy as neoadjuvant treatment, followed by pembrolizumab vs placebo as adjuvant treatment for early triple-negative breast cancer: pathologic complete response in key subgroups. Abstract GS3-03. San Antonio: SABCS; 2019.

69 Schmid P, Cortes J, Pusztai L, McArthur H, Kümmel S, Bergh J, et al.; Keynote-522 Investigators. Pembrolizumab for aarly triple-negative breast cancer. N Engl J Med. 2020 Feb; 382(9):810-21.

70 Gianni L, Huang C-S, Egle D, et al. Pathologic complete response ( $\mathrm{pCR}$ ) to neoadjuvant treatment with or without atezolizumab in triple negative, early high-risk and locally advanced breast cancer: NeoTRIPaPDL1 Michelangelo randomized study. Cancer Res. 2020;80:abstract GS3-04

71 Robson M, Im SA, Senkus E, Xu B, Domchek SM, Masuda N, et al. Olaparib for metastatic breast cancer in patients with a germline BRCA mutation. N Engl J Med. 2017 Aug; 377(6):523-33.

72 Litton JK, Rugo HS, Ettl J, Hurvitz SA, Gonçalves A, Lee KH, et al. Talazoparib in patients with advanced breast cancer and a germline BRCA mutation. N Engl J Med. 2018 Aug; 379(8):753-63.

73 Litton JK, Scoggins ME, Hess KR, Adrada BE, Murthy RK, Damodaran S, et al. Neoadjuvant Talazoparib for Patients With Operable Breast Cancer With a Germline BRCA Pathogenic Variant. J Clin Oncol. 2020 Feb;38(5):388-94.

74 Fasching PA, Jackisch C, Rhiem K, Schneeweiss A, Klare P, Hanusch C, et al. GeparOLA: a randomized phase II trial to assess the efficacy of paclitaxel and olaparib in comparison to paclitaxel/carboplatin followed by epirubicin/cyclophosphamide as neoadjuvant chemotherapy in patients (pts) with HER2-negative early breast cancer (BC) and homologous recombination deficiency (HRD). J Clin Oncol. 2019;37:506

75 Schmid P, Abraham J, Chan S, Wheatley D, Brunt AM, Nemsadze G, et al. Capivasertib Plus Paclitaxel Versus Placebo Plus Paclitaxel As First-Line Therapy for Metastatic TripleNegative Breast Cancer: the PAKT Trial. J Clin Oncol. 2020 Feb;38(5):423-33.

76 Kim SB, Dent R, Im SA, Espié M, Blau S, Tan $\mathrm{AR}$, et al.; LOTUS investigators. Ipatasertib plus paclitaxel versus placebo plus paclitaxel as first-line therapy for metastatic triple-negative breast cancer (LOTUS): a multicentre, randomised, double-blind, placebo-controlled, phase 2 trial. Lancet Oncol. 2017 Oct; 18(10):1360-72.

77 Tripathy D, Chien AJ, Hylton N et al. Adaptively randomized trial of neoadjuvant chemotherapy with or without the Akt inhibitor MK-2206: graduation results from the I-SPY 2 trial. J Clin Oncol. 2015;33:524.

78 Oliveira M, Saura C, Nuciforo P, Calvo I, Andersen J, Passos-Coelho JL, et al. FAIRLANE, a double-blind placebo-controlled randomized phase II trial of neoadjuvant ipatasertib plus paclitaxel for early triple-negative breast cancer. Ann Oncol. 2019 Aug;30(8):1289-97. 